\title{
AHP JAKO METODA EKONOMII EKSPERYMENTALNEJ
}

\author{
MARIA PARLIŃSKA ${ }^{1}$, ŁUKASZ PIETRYCH $^{2}$ \\ Szkoła Główna Gospodarstwa Wiejskiego w Warszawie \\ Wydział Nauk Ekonomicznych \\ 1 e-mail: maria_parlinska@sggw.pl \\ 2 e-mail: lukasz_pietrych@sggw.pl
}

\begin{abstract}
SŁOWA KLUCZOWE $\mid$ Analityczny Proces Hierarchiczny, ekonomia eksperymentalna
\begin{tabular}{l|l} 
STRESZCZENIE & W pracy dokonano charakterystyki metody AHP jako narzędzia wspierającego po-
\end{tabular} dejmowanie decyzji wielokryterialnych. W dalszej części przybliżono zagadnienia metodyczne warunkujące przeprowadzenie poprawnego eksperymentu ekonomicznego. Wykazano, że metoda AHP znajduje zastosowanie w ekonomii eksperymentalnej. Prowadzone badania empiryczne mogą być również oparte na różnego rodzaju symulacjach komputerowych.
\end{abstract}

\section{Wprowadzenie}

W obecnych czasach problematyka związana z procesem podejmowania decyzji jest obszarem analiz w takich dyscyplinach jak medycyna (neurologia i psychologia), ale także ekonomia i matematyka. O aktualności tego zagadnienia świadczą również Nagrody Nobla przyznane w dziedzinie ekonomii w ostatnich latach. Można wymienić tutaj nagrodę z 2002 roku dla Daniela Kahnemana za zastosowanie eksperymentów laboratoryjnych w analizie ekonomicznej 
z uwzględnieniem procesów decyzyjnych w warunkach niepewności - wspólnie z Vernonem Smithem. Innym przykładem jest nagroda z 2000 roku dla Daniela McFaddena, który badał decyzje podejmowane przez jednostki przy użyciu metod statystycznych. Ścisły związek z podejmowaniem decyzji ma również teoria gier oraz ekonomia eksperymentalna.

Jak stwierdza Krawczyk, eksperyment, najogólniej ujmując, jest jedną z podstawowych metod zdobywania wiedzy naukowej (Krawczyk, 2010, s. 9). Polega na sztucznym wywoływaniu jakiegoś zjawiska ekonomicznego, zazwyczaj sprowadzanego do pewnego problemu decyzyjnego, a następnie jego obserwacji, co pozwala na formułowanie wniosków co do jego przebiegu i właściwości (Poskrobko, 2012, s. 108).

Z kolei Analityczny Proces Hierarchiczny (AHP) jest wielokryterialną metodą wspomagania procesu decyzyjnego. W przypadku tego rodzaju metod należy uwzględnić szereg różnych kryteriów mających wpływ na podejmowane decyzje. Umożliwia ona dekompozycję złożonego problemu decyzyjnego oraz utworzenie rankingu finalnego dla rozpatrywanych wariantów decyzyjnych (Omkarprasad, Sushil, 2006, s. 1-2).

Celem pracy jest wykazanie, że metoda AHP może być narzędziem ekonomii eksperymentalnej. Szerokie zastosowanie tej metody we wspomaganiu decyzji ekonomicznych, technicznych czy społecznych potwierdza jej celowość. W niniejszym artykule przedstawiona została metoda AHP oraz praktyczny przykład wykorzystania tego narzędzia w rozwiązaniu wielokryterialnego problemu decyzyjnego. Autorzy skupili szczególną uwagę na powiązaniach tej metody z ekonomią eksperymentalną.

\section{Analityczny Proces Hierarchiczny}

W literaturze przedmiotu opisano jak do tej pory wiele metod rozwiązywania problemów wielokryterialnych (ang. multicriterion decision aid - MCDA). Do najczęściej wykorzystywanych metod tego typu można zaliczyć: programowanie wielokryterialne, ELECTRE (ang. Elimination and Choice Translating Reality) I, II, III, IV, PROMETHEE I, II, MAPACC, PRAGMA, sztuczne sieci neuronowe, DEA (ang. Multi Criteria Decision Analysis), VDA (ang. Verbal Decision Analysis), AHP (ang. Analytic Hierarchy Process), ANP (ang. Analytic Network Process) (Adamus, Łasak, 2010 s. 77). Każda z nich ma zalety, jak również pewne ograniczenia. Kluczową kwestią jest również dobór odpowiedniej metody w zależności od specyfiki danego problemu decyzyjnego. Guitouni oraz Martel stwierdzają, że pomimo opracowania wielu metod zaliczanych do grupy MCDA nie jest możliwe wyróżnienie tej jednej uniwersalnej, która mogłaby być stosowana do każdego problemu decyzyjnego. Celem ich badań było określenie pewnych wytycznych dla wyboru odpowiedniej metody MCDA (Guitouni, Martel, 1997, s. 501).

Metoda AHP bazuje na własnościach macierzy oraz wektorów, które je tworzą. Budowane są one na podstawie ocen ekspertów z danej dziedziny, którzy dokonują porównań parami wszystkich elementów struktury. Metoda ta została opracowana przez Thomasa Saaty'ego w latach 70 . 
W Analitycznym Procesie Hierarchicznym podstawą jest zbudowanie dla konkretnego problemu decyzyjnego struktury hierarchicznej. Jest ona podzielona na kilka poziomów. Na szczycie znajduje się cel główny, niżej umieszczane są kryteria (w ich ramach można wyróżnić subkryteria), natomiast najniższy poziom tworzą warianty decyzyjne, czyli możliwe rozwiązania. Ważne jest, aby ta struktura opisywała problem decyzyjny w sposób całościowy, bez pominięcia ważnych aspektów, które mogą wywierać silny wpływ na skutki ewentualnej decyzji (Łuczak, Wysocki, 2008, s. 48-49).

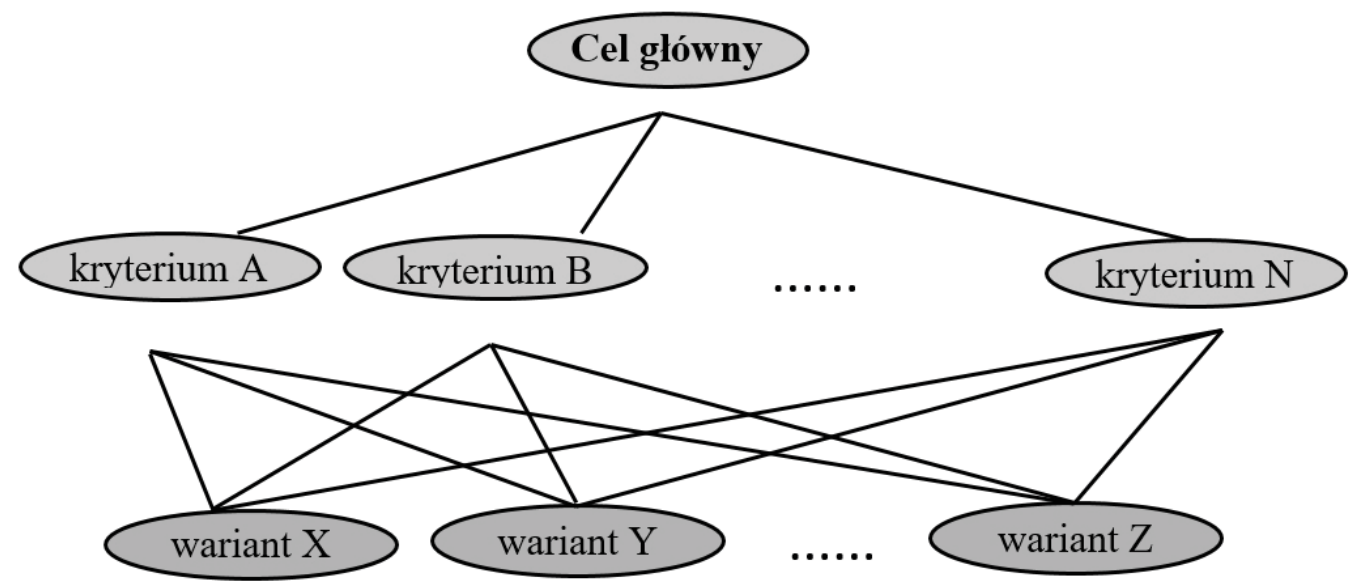

Rysunek 1. Struktura hierarchiczna

Źródło: opracowanie własne na podstawie (Łuczak, Wysocki, 2008, s. 49).

W następnym etapie istotną rolę odgrywają eksperci oraz ich indywidualne preferencje. W metodzie AHP preferencje decydenta określane są przy pomocy względnych ocen ważności kryteriów i wariantów. Odbywa się to na zasadzie porównania parami czynników z tego samego poziomu względem kryterium, które znajduje się bezpośrednio wyżej. Otrzymane w ten sposób wyniki porównań parami można zapisać w macierzy preferencji. Twórca metody zaproponował w celu wyrażenia ocen dziewięciostopniową skalę (Bodin, Gass, 2003, s. 1484). Jest to kluczowy moment, który pozwala w sposób ilościowy dokonać tych porównań. Każdemu stopniowi w skali zostało przypisane znaczenie słowne, co bardzo ułatwia postępowanie podczas dokonywania ocen (ekspert może najpierw dokonać porównania werbalnie, później dopiero przypisać odpowiednią wartość liczbową). 
Tabela 1. Skala Saaty'ego

\begin{tabular}{ll}
\hline \multicolumn{1}{c}{ Skala } & \multicolumn{1}{c}{ Objaśnienie } \\
\hline 1 & brak możliwości wyróżnienia elementu dominującego \\
3 & jeden z elementów ma nieznacznie większe znaczenie \\
5 & wyraźna przewaga jednego z elementów nad drugim \\
7 & bardzo znacząca przewaga jednego z elementów nad drugim \\
9 & absolutna przewaga jednego z elementów nad drugim \\
$2,4,6,8$ & wartości pośrednie (stosuje się, gdy występuje problem z jednoznacznym użyciem któregoś \\
& z elementów skali powyżej) \\
Odwrotności & dla porównań w przeciwną stronę \\
\hline
\end{tabular}

Źródło: opracowanie własne na podstawie (Saaty, 2008, s. 86).

Kolejnym krokiem w procedurze jest wyznaczenie priorytetów globalnych i lokalnych dla poszczególnych elementów struktury. Jednak aby je obliczyć, należy najpierw znaleźć wektory własne oraz wartości własne macierzy porównań, wykorzystując zagadnienia z algebry liniowej. Saaty zaproponował kilka innych metod, które w sposób mniej skomplikowany dają przybliżone wyniki. Jedna z nich polega na przemnożeniu przez siebie wszystkich elementów z każdego z wierszy oddzielnie oraz wyciągnięcie dla każdego iloczynu pierwiastka, którego stopień jest równy liczbie tych elementów (a co za tym idzie - także stopniowi macierzy, ze względu na to, że wszystkie analizowane macierze muszą być symetryczne). W kolejnym kroku uzyskane wyniki normalizuje się do jedności, poprzez podzielenie ich przez sumę wszystkich pierwiastków otrzymanych wcześniej. Tak otrzymane znormalizowane wyniki są przybliżonymi wektorami własnymi macierzy (Saaty, Kearns, 1991, s. 31-32). W literaturze metoda ta nazywana jest metodą logarytmicznych najmniejszych kwadratów (lub średniej geometrycznej). Znane są jednak również inne podejścia, m.in. metoda najmniejszych kwadratów, sum kolumnowych, metody ważone, układy równań liniowych oparte na minimalizacji odległości (Zakaria, Dahlan, Hussin, 2012, s. 555).

Obliczone w któryś z wyżej wymienionych sposobów wektory własne są tzw. priorytetami lokalnymi. Na najwyższym poziomie struktury, czyli poziomie porównań kryteriów względem celu głównego, priorytety lokalne są jednocześnie globalnymi i wyrażają to, które z wymienionych kryteriów ma największe znaczenie w kontekście sformułowanego celu. Na najniższym poziomie, gdzie umiejscowione są warianty decyzyjne, postępuje się podobnie. Wielkości są bardzo ważne, gdyż łączą one ze sobą element z najwyższego poziomu z elementami poziomu najniższego, co sprawia, że cała struktura jest spójną całością. Priorytet z najwyższą wartością uznaje się za najkorzystniejszy (Adamus, Łasak, 2010, s. 81-82).

Kolejnymi wartościami uzyskiwanymi z działań przeprowadzanych na macierzach porównań są: $\lambda_{\max }$, indeks C.I. (Consistency Index), oraz współczynnik C.R. (Consistency Ratio). Największa wartość własna macierzy, czyli $\lambda_{\max }=\max \left\{\lambda_{1}, \lambda_{2}, \lambda_{3}, \ldots, \lambda_{n}\right\}$, gdzie $n-$ liczba pierwiastków wielomianu charakterystycznego określa stopień zgodności porównań parami, czyli to, czy są one konsekwentne i nie wykluczają siebie nawzajem. W literaturze zaleca się, aby $\lambda_{\max }=n$ 
(wartość własna macierzy jest równa rzędowi macierzy), ponieważ wówczas występuje całkowita zgodność ocen (Saaty, Ozdemir, 2003, s. 240).

Na podstawie $\lambda_{\max }$ oblicza się indeks niezgodności, czyli poziom odchylenia od pożądanej spójności. Wyraża się go wzorem:

$$
C I=\frac{\left(\lambda_{\max }-n\right)}{n-1}
$$

Na podstawie tego indeksu buduje się współczynnik C.R., który jest łatwiejszy w interpretacji, gdyż w procentach wyraża, w jakim stopniu porównania elementów danego poziomu struktury są niezgodne względem siebie (brak konsekwencji w ich analizie). Oblicza się go ze wzoru:

$$
\text { C.R. }=100 \% \times \frac{\text { C.I. }}{\text { R.I. }}
$$

gdzie za R.I. (ang. Random Index) przyjmuje się tzw. losowy indeks niezgodności. Jest on obliczany z próby, na którą składają się losowo wybrane macierze (Adamus, Łasak, 2010, s. 82).

Tahela 2. Wartości współczynnika R.I. dla próby 10000

\begin{tabular}{cccccccccccccccc}
\hline $\mathrm{n}$ & 1 & 2 & 3 & 4 & 5 & 6 & 7 & 8 & 9 & 10 & 11 & 12 & 13 & 14 & 15 \\
\hline R.I. & 0 & 0 & 0,52 & 0,89 & 1,11 & 1,25 & 1,35 & 1,40 & 1,45 & 1,49 & 1,52 & 1,54 & 1,56 & 1,58 & 1,59 \\
\hline Źródło:
\end{tabular}

Źródło: opracowanie własne na podstawie (Saaty, Ozdemir, 2003, s. 241).

Zaleca się, aby wartość współczynnika niezgodności dla macierzy o wymiarach większych niż $4 \times 4$ nie była większa niż $10 \%$, dla macierzy $4 \times 4-8 \%$, natomiast dla macierzy $3 \times 3-5 \%$. Przekroczenie tych progów wskazuje na to, że oceny nie są konsekwentne i powinny być powtórzone (Parlińska, 2008, s. 99). Z drugiej strony jednak należy zauważyć, że w praktyce sytuacja gdy $C . R .=0$, czyli sytuacja braku jakiejkolwiek niezgodności, również jest niekorzystna, gdyż w realnym problemie decyzyjnym decydenci ciągle zdobywają nową wiedzę i nabywają nowe umiejętności, co może skutkować zmianą opinii na dany temat (Adamus, Łasak, 2010, s. 82).

\section{Przyklad symulacij}

W literaturze został już ukształtowany pewien stan badań w zakresie stosowania MCDA w ekonomii eksperymentalnej. Przykładowo Løken za pomocą eksperymentu porównywał zastosowanie dwóch metod MCDA do projektowania systemu energetycznego uwzględniającego preferencje konsumentów. Umożliwiło to wyszczególnienie ich zalet. Przeprowadzone eksperymenty wykazały, że różne metody wyszczególnione w ramach grupy MCDA nie muszą prowadzić do takich samych wyników. Różnice te mogą być spowodowane m.in. różnym sposobem zadawania pytań, stopniem trudności danej procedury czy też różnym sposobem wyrażania preferencji. Jednakże metoda AHP okazała się najefektywniejsza, głównie ze względu na mało skomplikowaną procedurę (Løken, 2007, s. 5-6). Poniżej zaprezentowano inny prosty przykład zastosowania tej metody. 
Na rysunku 2 przedstawiono strukturę dla problemu wyboru samochodu, przyjmując cztery kryteria. Rozpoczynając przedmiotową analizę, określono następujące kryteria wyboru:

Cena $\rightarrow(1)$

Spalanie $\rightarrow(2)$

Komfort $\rightarrow(3)$

Design $\rightarrow(4)$

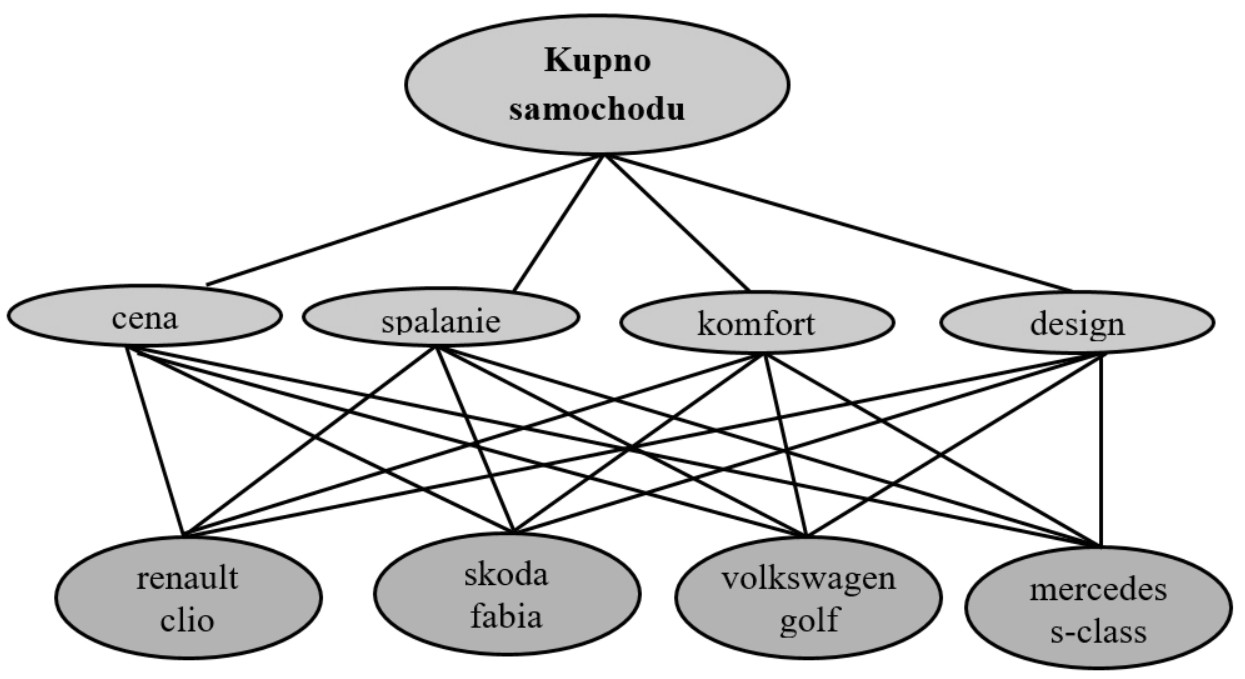

Rysunek 2. Struktura hierarchiczna dla przykładowego problemu decyzyjnego

Źródło: opracowanie własne.

Tym samym nadaje się im wagę (wartość w nawiasach), która była główną determinantą. W tym przykładzie założono, że była to cena samochodu (wartość początkowa kupowanego samochodu zgodnie z ustawą o rachunkowości). Wartość tego kryterium wyniosła 0,48 . Natomiast najmniej istotnym czynnikiem $(0,11)$ i jednocześnie najbardziej subiektywnym był design. Biorąc pod uwagę fakt, że kryterium ceny i spalania stanowiły 0,63 wagi punktowej, modelem samochodu, który w tych kategoriach okazał się najbardziej ekonomiczny, był renault clio. To te dwa czynniki w zdecydowanej mierze wpłynęły na ranking.

Kolejnym aspektem obliczeń przy zastosowaniu metody AHP jest fakt, że samochody skoda fabia i volkswagen golf, będące tymi samymi samochodami w swojej klasie, działające w ramach jednej grupy producenckiej, uzyskały niemalże takie same wyniki. Dopiero czwarte miejsce po przecinku wykazało różnice punktowe (skoda fabia - 0,2090 i volkswagen golf-0,2094).

Ostatnim analizowanym samochodem był mercedes s-class. Mercedes uzyskał najwyższe współczynniki komfortu $(0,56)$ i designu $(0,41)$, ale ich wagi przy wyborze najlepszego samochodu w ostatecznym rankingu w stosunku do dwóch pozostałych kryteriów były mało znaczące. 
To spowodowało, że zajął on ostatnie miejsce. Gdyby zespół decyzyjny nadał najwyższe wagi innym kategoriom, mercedes byłby niekwestionowanym liderem.

W metodzie AHP utworzono ranking finalny dla skończonego zbiór wariantów, w wyniku czego dokonano następującej klasyfikacji możliwych do wyboru samochodów:

Tahela 3. Ranking ważności kryteriów

\begin{tabular}{ccc}
\hline Wariant & Pozycja & Priorytet (waga) \\
\hline renault clio & I & 0,335 \\
skoda fabia & II & 0,209 \\
volkswagen golf & III & 0,209 \\
mercedes s-class & IV & 0,247 \\
\hline
\end{tabular}

Źródło: opracowanie własne.

\section{Podsumowanie}

Smith opracował podstawy metodyczne eksperymentu jako narzędzia badawczego w ekonomii. Wyróżnił on trzy czynniki, które definiują eksperyment ekonomiczny: środowisko, instytucje oraz zachowanie uczestników eksperymentu (Smith, 1994, s. 113). Te trzy czynniki stanowią podstawowe składowe dla konstrukcji poprawnego metodycznie eksperymentu ekonomicznego. Można stwierdzić, że zaprezentowany przykład wyboru wariantu za pomocą metody AHP spełnia te trzy podstawowe elementy eksperymentu. Na środowisko składają się tzw. warunki początkowe, czyli w tym przypadku układ preferencji oraz bodźce motywujące w odpowiedni sposób do racjonalnego zachowania. Instytucje z kolei regulują zasady komunikacji pomiędzy uczestnikami eksperymentu. Od strony technicznej można stwierdzić, że zawarte są one w pewnych instrukcjach oraz procedurach obsługiwanych za pomocą odpowiedniego oprogramowania. W przypadku metody AHP niezbędne jest także, aby przed przystąpieniem do hierarchizacji kryteriów oraz wariantów poinstruować wybraną grupę na temat przebiegu tego etapu badania.

Wychodząc od ogólnej charakterystyki, klasyczny eksperyment ekonomiczny składa się z kilku do kilkunastu sesji. Każda sesja z kolei przebiega według określonego schematu: zajęcie miejsc w sali komputerowej przez uczestników badania, wręczenie pisemnych procedur opisujących dany problem decyzyjny, uruchomienie programu komputerowego umożliwiającego podejmowanie decyzji. Jeżeli dany eksperyment jest skomplikowany, niekiedy zaleca się, aby uczestnicy przeszli jedną lub kilka rund testowych $\mathrm{w}$ celu zaznajomienia się z instrukcjami (Krawczyk, 2010, s. 19). W przypadku metody AHP podstawowym oprogramowaniem służącym do wyznaczenia wag lokalnych i globalnych jest program Expert Choice. Dokonywanie ocen może odbywać się w oknie dialogowym wygenerowanym przez ten program bądź też na przygotowanym kwestionariuszu.

Ważnym etapem badania eksperymentalnego jest zdefiniowanie zmiennych wyjaśniających dane zjawisko ekonomiczne. W literaturze wyróżnia się dwa rodzaje zmiennych: zmienne 
eksperymentalne (podlegające manipulacji) oraz zmienne zależne, które stanowią odzwierciedlenie danego problemu. Zmienne pierwszego rodzaju mogą przyjmować wartości mierzone na różnych poziomach, w zależności od potrzeb danej rundy. W trakcie badania mogą być również wprowadzone tzw. kontrolne poziomy zmiennej. Stosuje się je w celu weryfikacji, czy badani podejmują decyzje zgodne z teorią ekonomiczną (Krawczyk, 2010, s. 43). Każdy problem decyzyjny analizowany za pomocą metody AHP wymaga podejścia polegającego na jego dekompozycji. Wyszczególnione kryteria stanowią zarówno zmienne eksperymentalne, jak i zależne, czyli te, które określają warunki bazowe dla danego problemu ekonomicznego.

$\mathrm{Na}$ wyżej wymienionych etapach badania eksperymentalnego można stosować również metody symulacji komputerowej. Łatuszyńska podkreśla, że symulacja komputerowa może być nie tylko narzędziem wspierającym eksperyment laboratoryjny, ale wręcz może go zastępować (Łatuszyńska, 2015, s. 9).

Podsumowując, można stwierdzić, że Analityczny Proces Hierarchiczny może być stosowany w badaniach eksperymentalnych. Metodę tę można stosować nie tylko do wspomagania podejmowania decyzji w rzeczywistości gospodarczej, ale również do symulacji i prezentacji pewnych możliwych rozwiązań. Mimo pewnych ograniczeń ma coraz to szersze zastosowanie oraz wysoką skuteczność.

\section{Literatura}

Adamus, W., Łasak, P. (2010). Zastosowanie metody AHP do wyboru umiejscowienia nadzoru nad rynkiem finansowym. Bank i Kredyt, 41(4), 73-100.

Bodin, L., Gass, S.I. (2003). On teaching the analytic hierarchy process. Computers \& Operations Research, 30, 14871497.

Guitouni, A., Martel, J. (1997). Tentative guidelines to help choosing an appropriate MCDA method. European Journal of Operational Research, 109 (1998), 501-521.

Krawczyk, M. (red.). (2010). Ekonomia eksperymentalna. Warszawa: Oficyna a Wolters Kluwer business.

Løken, E. (2007). Multi-Criteria Planning of Local Energy Systems with Multiple Energy Carriers. Thesis for the degree philosophiae doctor. Pobrane z: https://www.sintef.no/globalassets/project/seds/espen-loken_thesis.pdf (12.10.2016).

Łatuszyńska, M. (2015). Symulacja komputerowa w ekonomii eksperymentalnej. Zeszyty Naukowe Uniwersytetu Szczecińskiego, 36, 5-18.

Łuczak, A, Wysocki, F. (2008). Wykorzystanie Analitycznego Procesu Hierarchicznego w analizie systemu motywacyjnego przedsiębiorstwa transportowego. Uniwersytet Przyrodniczy w Poznaniu, Journal of Agribusiness and Rural Development, 4(10), 47-60.

Omkarprasad, S.V., Sushil, K. (2006). Analytic hierarchy process: An overview of applications. European Journal of Operational Research, 169, 1-29.

Parlińska, M. (2008). Rola informacji w gospodarce rynkowej na podstawie wybranych rolnych rynków hurtowych. Warszawa, Wydawnictwo SGGW.

Poskrobko, T. (2012). Nowe koncepcje i teorie rozwoju w ekonomii. W: S. Czaja, A. Becla, T. Poskrobko, J. Włodarczyk, Wyzwania wspótczesnej ekonomii. Difin, Warszawa.

Saaty, T.L., Kearns, K.P. (1991). Analytical planning. The Organization of Systems. Pittsbourgh: RWS Publications.

Saaty, T.L. (2008). Decision making with the analytic hierarchy process. International Journal of Services Sciences, 1, 1,83-98. 
AHP jako metoda ekonomii eksperymentalnej

Saaty, T.L., Ozdemir, M. (2003). Why the magic number seven plus or minus two. Mathematical and Computer Modelling, 38, 233-244

Smith, V. (1994). Economics in the laboratory. Journal of Economic Perspectives, 8, 1, 113-131.

Zakaria, N.F., Dahlan, H.M., Hussin, A.R.C. (2012). Prioritization method in the analytic hierarchy process using evolutionary computing. International Journal of Innovative Computing, 1, 555-560.

\section{AHP AS A METHOD OF EXPERIMENT ECONOMIC}

\section{KEYWORDS | Analytic Hierarchy Process, experimental economics}

ABSTRACT The study characterized the AHP method as a tool to support decision-making. The next section discusses the methodological issues conditioning to carry out proper economic experiment. It has been shown that the method of AHP is used in experimental economics. Empirical studies can also be conducted on the basis of various types of computer simulations. 